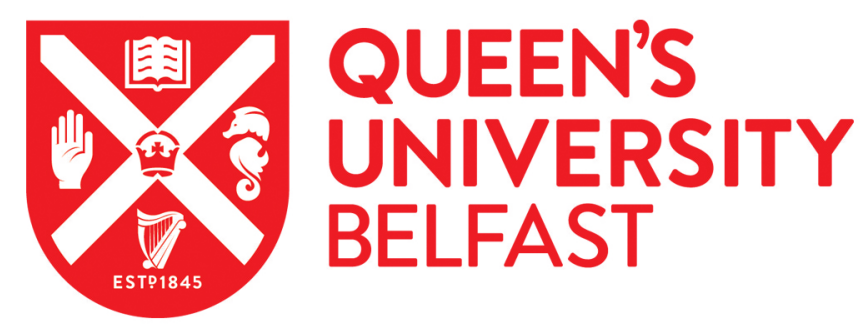

\title{
The extent of stability and relational permanence achieved for young children in care in Northern Ireland
}

McSherry, D., \& Fargas Malet, M. (2018). The extent of stability and relational permanence achieved for young children in care in Northern Ireland. Children Australia, 43(2), 124-134. https://doi.org/10.1017/cha.2018.18

\author{
Published in: \\ Children Australia
}

\section{Document Version:}

Peer reviewed version

Queen's University Belfast - Research Portal:

Link to publication record in Queen's University Belfast Research Portal

\section{Publisher rights}

Copyright 2018 The Authors.

This manuscript is distributed under a Creative Commons Attribution-NonCommercial-NoDerivs License

(https://creativecommons.org/licenses/by-nc-nd/4.0/), which permits distribution and reproduction for non-commercial purposes, provided the author and source are cited.

\section{General rights}

Copyright for the publications made accessible via the Queen's University Belfast Research Portal is retained by the author(s) and / or other copyright owners and it is a condition of accessing these publications that users recognise and abide by the legal requirements associated with these rights.

Take down policy

The Research Portal is Queen's institutional repository that provides access to Queen's research output. Every effort has been made to ensure that content in the Research Portal does not infringe any person's rights, or applicable UK laws. If you discover content in the Research Portal that you believe breaches copyright or violates any law, please contact openaccess@qub.ac.uk. 
The extent of stability and relational permanence achieved for young children in care in Northern Ireland

Dr Dominic McSherry

Senior Research Fellow

School of Social Sciences, Education and Social Work

Queen's University Belfast

Northern Ireland

BT7 1LP

e-mail: Dominic.mcsherry@qub.ac.uk

(Corresponding author)

Dr Montserrat Fargas Malet

Research Fellow

School of Social Sciences, Education and Social Work

Queen's University Belfast

Northern Ireland

BT7 1LP

e-mail: m.fargas@qub.ac.uk 


\section{Abstract}

Placement stability is sought for children who enter care and need a place to call home. This is deemed to be necessary for the formation and continuation of secure and loving relationships with parents and carers. However, the term placement stability does not capture the quality of the placement or the subjective experience of the young person. In contrast, the term relational permanence denotes an enduring and supportive relationship between a young person and a caring adult. Research studies have tended to focus on placement stability, or legal and physical permanence, and overlook relational permanence. Within the current study, we found high levels of long-term placement stability for the study population, 354 young people who were under five and in care in Northern Ireland on the $31^{\text {st }}$ March 2000. Placements for those who were adopted, on Residence Order, and rehabilitated with birth parents were more likely to be stable than those in long-term foster care and kinship foster care. However, early interview data with 30 young people and/or their parents/carers revealed high levels of relational permanence, irrespective of placement type, and that placement disruption did not necessarily mean a breakdown in the relationship. Implications for policy and practice are discussed. 
The extent of stability and relational permanence achieved for young children in care in Northern Ireland

\section{Introduction}

When a child is removed from their birth parents, Social Services aim to provide them with stability and thus a permanent home as soon as possible, so they can develop positive attachment relationship with a parent or parental figure. Thus, it is commonly acknowledged that continuity of attachments in early childhood is likely to lead to better outcomes throughout life (Aldgate \& Jones, 2005; Rutter, 1995). However, permanence in terms of placement stability may not always equate to a more subjective permanence, where the fine quality and strength of relationships are preserved, regardless of remaining physically in the same home (Beek, 2014). In this paper, we explore the extent of placement stability for a population $(n=354)$ of young people who entered care at a young age in Northern Ireland. In addition, we provide an initial account of the extent to which relational permanence was achieved for a smaller sample of young people (who had been interviewed by the time that this paper was developed) across the different types of placements.

\section{Placement stability}

Multiple moves in care are likely to result in several poor outcomes for children and young people (e.g. Rubin et al., 2007; Ward, Munro, \& Dearden, 2006). Various research studies have compared stability across different types of placements, sometimes with contradictory results. For instance, on the one hand, Thoburn (1991) argued that there was no difference in breakdown rates between children placed for adoption and those in "permanent" foster families, and Triseliotis (2002) showed a reduction of the differences in disruption rates between adoption and long-term foster care as older and more difficult children were adopted. However, on the other hand, many recent studies have found substantial differences between the two, with foster care placements being more likely to disrupt than adoption placements (e.g., Biehal et al., 2010; Sellick et al., 2004; Selwyn \& Quinton, 2004; Sinclair, 2005; Ward et al., 2003; Wilson et al., 2004). The level of instability that some studies 
have found for children in the care system has led some to call for a re-think on entry to the care system itself (Ainsworth \& Hansen, 2014).

Regarding the latest statistics on placement stability in Northern Ireland, during the year ending $30^{\text {th }}$ September 2016, 19\% ( $n=415)$ of all children in care for 12 months or longer changed placement at least once. For half of these children, the latest placement change was planned, while $42 \%$ were due to a breakdown and $8 \%$ for other reasons. Three fifths $(62 \%)$ of all placement moves for the $12-$ 15 year age group were due to placement breakdown. During the year ending $31^{\text {st }}$ March 2017, 120 children were adopted from care in Northern Ireland but there are no publically available statistics on the stability of adoption placements. However, a recent study found that over a 12 -year old period, the disruption rate in England was 3.2\% (Selwyn, Wijedasa, \& Meakings, 2014). 


\section{Relational permanence}

While various studies have found that foster care and kinship foster care placements provide security and a sense of belonging in a family for children in care (McSherry, Fargas Malet \& Weatherall, 2013; 2016; Schofield, 2003; Schofield \& Beek, 2009), a range of scholars have stressed the insecurity and instability of foster placements, particularly when compared to adoptive placements (Selwyn \& Quinton, 2004; Selwyn et al., 2006; Sinclair et al., 2000, 2003; Triseliotis, 2002). Particularly in the US and the UK, adoption has typically been deemed as the only placement where children can achieve a family for life, as permanence is guaranteed due to its legal status, and it has been elevated to the top of a "hierarchy of permanency", next to reunification (Lowe et al., 2002; Thompson \& Greeson, 2015). However, this overlooks the subjective sense of permanent belonging to a family that a young person may also experience in other types of long-term placement, such as foster care and kinship foster care (Thomas \& Greeson, 2015). Moreover, as Beek (2014) pointed out, permanence can occur without continuity of placement, while placement stability does not necessarily imply that the young person feels secure or part of that family.

Consequently, scholars have distinguished between different aspects of permanence. For instance, in the United States, Sanchez (2004) distinguished between legal, physical and emotional permanence. While legal permanence can only be achieved through either reunification to birth parents or adoption (or, in England, special guardianship, and in the US, transfer of legal guardianship), physical permanence involves the young person living continuously with the same caregivers, and relational permanence reflects the young person's enduring parent-like connection to caring adults (Semanchin Jones \& LaLiberte, 2013).

Similarly, in England, Sinclair et al. (2005) distinguished between objective permanence (i.e. placement to last until 18), subjective permanence (i.e. where child felt part of the family), enacted permanence (i.e. where all concerned felt and acted as if child was part of the family), and 
uncontested permanence (i.e. where child did not feel troubled about their loyalty to the birth family).

The majority of research studies have focused on legal and physical (or objective) permanence, whereas relational (or subjective and enacted) permanence has frequently been overlooked, despite being identified as the most important aspect of permanence for young people leaving care (Samuels, 2009; Sanchez, 2004; Semanchin Jones \& LaLiberte, 2013). In fact, "felt security in care" (sense of being loved and of belonging) and social support after leaving care, rather than stability in care (which was not as important), were the main predictors of positive outcomes for care leavers (4-5 years after leaving care) in an Australian longitudinal study (Cashmore \& Paxman, 2006).

Although a vast amount of research has been conducted on the causes and risk factors for placement breakdown in foster/kinship care (Andersen \& Fallesen, 2015; Oosterman et al., 2007; Rock, Michelson, Thomson, \& Day, 2013; Vinnerljung, Sallnäs, \& Berlin, 2017), very little is known about what happens after children move out of their placements, particularly if they had been living there for an extended period of time (long-term placement). Does the relationship with and the feeling of belonging to that family disappear forever at the point of breakdown/disruption? Do these relationships end when the child moves out? There is some evidence that this is often not the case (Hedin, 2017; Thoburn et al., 2000), and this article presents findings that contribute to our knowledge base on this issue.

\section{The Care Pathways and Outcomes Study}

The Care Pathways and Outcomes Study is a longitudinal study that has been following a population $(n=374)$ children who were under five years old and in care in Northern Ireland on $31^{\text {st }}$ March 2000. The study is concerned with examining placement patterns and exploring the experiences of these children and their parents/carers across the full range of placement options, i.e. foster care, kinship foster care (with relatives), adoption, living with birth parents, and Residence Order (where the 
named carer shares parental responsibility with the birth parents for as long as the order is in place), throughout childhood, and into early adulthood.

Three waves of the study have been completed to date. Wave One (2000-2003) examined data from Social Services case files enabling a detailed picture of each child's background, family history and placement history to be built up. Wave Two (2003-2006) sought the perspectives of birth, adoptive, and foster parents/carers in order to look at how the children were faring in their placements. Wave Three (2006-2010) examined children's (then aged 9 -14) own accounts of their lives and experiences within their different types of placement, and explored their views on a variety of issues. The perspectives of their parents/carers were also sought for a second time (McSherry, Fargas Malet \& Weatherall, 2013; 2016). Wave Four (2016-2019) is currently examining the lives of these young people when they are aged between 18 and 22 years old. This paper is focused on findings from the initial stages of data collection from Wave Four, specifically focusing on the issues of placement stability and relational permanence.

\section{Method}

\section{Design}

This is a prospective longitudinal study that employs a mixed methods approach to exploring the perspectives of young people and their parents/carers, allowing for triangulation of data.

\section{Participants}

The study sample for Wave Four of the study consists of the same population of children that has been tracked in the previous three waves of the study. The study operates in two stages. Stage 1 involves the development of a placement profile for the full study population on the basis of placement data provided by Social Services through to the $31^{\text {st }}$ March 2016. Data has been received for $95 \%(n=354)$ of the original study population. At that point ( $31^{\text {st }}$ March 2016), 63\% ( $\left.n=259\right)$ of 
the young people were 18 years or older, whilst $27 \%(n=95)$ were still under 18 (either 16 or 17 years old).

Stage 2 involves interviews with the young people and their parents and carers. It is anticipated that interviews will be conducted with $50 \%(n=177)$ of the study population. This process is ongoing. Participants are being recruited through Social Services and Adoption UK (a leading UK nongovernmental adoption advocacy organisation). These agencies send recruitment packs (containing an introductory letter and participant information sheets for young people and parent/carers) to the families in the study population on behalf of the research team. To date, quantitative data has been collected for 39 families, and qualitative data (i.e. semi-structured interview) for 30 of these. The qualitative analysis presented in this paper is based on these interviews. Data has been collected from 21 sets of young people and parents/carers, and in nine cases, from the parents/carers alone. In terms of placement types, the distribution is as follows: six Residence Order families (3 kinship and 3 non-kinship), seven foster carer families, four kinship carer families, 11 adoptive families and two birth parent families. Recruitment for the study commenced with that group of young people and parents/carers who were interviewed during the previous wave of the study. As such, all of the families had taken part previously with the exception of one adoptive parent.

\section{Data collection}

Care placement records from first entry to care (prior to the $31^{\text {st }}$ March 2000) through to the $31^{\text {st }}$ March 2016 were received from Social Services in Northern Ireland for 95\% ( $n=354)$ of the original study population $(n=374)$. The placement profile on the $31^{\text {st }}$ March had been specified at a number of points during previous waves of the study $(2000 ; 2002 ; 2004$; and 2007). The current profile enabled a tracking of placements, and any placement change, from 2007 through to March 2016, a further nine year period. Given that the study population were all under the age of five on the $31^{\text {st }}$ March 2000, many of them had already turned 18 by the time of the current profiling exercise. 
Each young person and their parent/s and carer/s are interviewed on two occasions. The first interview involves the use of an iPad to collect quantitative data in the form of an electronic questionnaire (one for young people and one for parents/carers), which combines a range of psycho-social measures. The second interview involves a semi-structured interview with the young people and their parents/carers separately. The interview with the young person examines the following issues: family and peer relationships; future aspirations and hopes; physical and mental health; leisure time and hobbies; supports and service provision; sense of belonging; contact with (and searching) birth family; and education. The interview with parents and carers examines similar issues, including: attachment, bonding and belonging; young person's health, including lifestyle; young person's education; supports and service provision; communication with the young person; and reflections on the young person's placement with them.

\section{Ethical approval}

Ethical approval for the study was granted by the Office of Research Ethics Committees in Northern Ireland (ORECNI).

\section{Data analysis}

IBM SPSS Statistics was used to analyse the placement data, with mainly descriptive analysis being conducted to date. As for the qualitative data, all interviews were audio-recorded and transcribed verbatim. Thematic analysis has been applied (Braun \& Clarke, 2006). Two researchers from the study read the transcripts and discussed the identified themes. All the names provided (even those within the quotes) in the results section are not the young people's real names but pseudonyms assigned by the research team, so confidentiality is assured. 


\section{Results}

\section{Placement stability}

The data utilised for tracking the study population is recorded by Social Services through to the age of 18 , at which point their statutory duties cease, and no further tracking occurs. Consequently, we specify this as the final point in our tracking process for the full population. It is the point where childhood legally ends and adulthood commences, so it is an appropriate termination point for a study that is focused on placement outcomes for young children in care through childhood. Of course, a key aspect of the current wave of the study is to understand where the young people live beyond the age of 18 , but this will only be possible with the sub-sample that we are able to interview, with a recruitment target of $50 \%(n=177)$ of the identified population $(n=354)$.

Within the current study, the term placement stability is understood in terms of the persistence of actual placement, rather than type of placement. For example, stability for a young person in foster care would mean remaining in the same foster placement, with the same foster parents/carers, and without a period of absence beyond a weekend respite episode.

Table 1 illustrates the degree of placement stability, across the different placement types, for the study population between $31^{\text {st }}$ March 2007 and either the point at which they turned 18 (before the $31^{\text {st }}$ March 2016), or the $31^{\text {st }}$ March 2016, for those still aged 16 and 17 years old. It also shows the level of stability for this older $(18+)$ and young group $(<18)$ combined. 
Table 1: Placement stability to 18 years old or at $31^{\text {st }}$ March 2016 (under 18s) by placement in 2007

(\%)

\begin{tabular}{|l|c|c|c|c|}
\hline $\begin{array}{l}\text { Placement 31st March } \\
2007\end{array}$ & $\begin{array}{c}\text { \% of population } \\
(n)\end{array}$ & $\begin{array}{c}\text { Stability } \\
2007 \text { to 18 } \\
\text { years old }\end{array}$ & $\begin{array}{c}\text { Stability to 31 } \\
\text { March 2016 } \\
(<18)\end{array}$ & $\begin{array}{c}\text { Combined } \\
\text { stability from } \\
2007 \text { (18 and } \\
<18)\end{array}$ \\
\hline Adoption & $44(n=157)$ & 70 & 27 & 97 \\
\hline Residence Order & $5(n=17)$ & 65 & 29 & 94 \\
\hline Birth parents & $23(n=82)$ & 60 & 26 & 86 \\
\hline Kinship foster care & $6(n=24)$ & 46 & 25 & 71 \\
\hline Foster care & $21(n=74)$ & 49 & 14 & 63 \\
\hline
\end{tabular}

Table 1 highlights very high levels of stability for those young people who were adopted, were placed on Residence Order, and who had been returned to birth parents, and lower, but still quite high levels, for those who were in foster or kinship foster care. Table 2 highlights the degree of stability for the study population across two time intervals; $31^{\text {st }}$ March 2002 to $31^{\text {st }}$ March 2007, and $31^{\text {st }}$ March 2007 to $18^{\text {th }}$ birthday or $31^{\text {st }}$ March 2016 (for under 18s). It also provides an overall level of stability since 2002 (covering a 14 year period). 
Table 2: Placement stability between 31 ${ }^{\text {st }}$ March 2002 and 31 ${ }^{\text {st }}$ March 2007, 31 ${ }^{\text {st }}$ March 2007 and 18th birthday or $31^{\text {st }}$ March 2016 (for under 18s) (\%), and over stability since 2002

\begin{tabular}{|l|c|c|c|}
\hline & & & \\
& & & \\
& Stability $2002-2007$ & years old or 31 $1^{\text {st }}$ & 2002 \\
Placement & & March $2016(<18)$ & $(14$ yrs $)$ \\
\hline Adoption & 89 & 97 & 86 \\
\hline Residence Order & 91 & 94 & 78 \\
\hline Birth parents & 91 & 86 & 55 \\
\hline Kinship foster care & 69 & 71 & 43 \\
\hline Foster care & & & \\
\hline
\end{tabular}

The percentages presented in Table 2 indicate the following:

- Of the $89 \%$ of young people who had been in the same adoptive placement (with same carers/parents) between 2002 and 2007, 97\% remained there, without disruption, until their $18^{\text {th }}$ birthday or the $31^{\text {st }}$ March 2016 (under 18s). This represents an overall stability level of $86 \%$ since 2002.

- Of the $91 \%$ of young people who had been in the same Residence Order placement between 2002 and $2007,94 \%$ remained there, without disruption, until their $18^{\text {th }}$ birthday or the $31^{\text {st }}$ March 2016 (under 18s). This represents an overall stability level of 86\% since 2002.

- Of the $91 \%$ of young people who had been in the same birth parent placement between 2002 and $2007,86 \%$ remained there, without disruption, until their $18^{\text {th }}$ birthday or the $31^{\text {st }}$ March 2016 (under 18s). This represents an overall stability level of 78\% since 2002. 
- Of the $78 \%$ of young people who had been in the same kinship foster care placement between 2002 and 2007, 71\% remained there, without disruption, until their $18^{\text {th }}$ birthday or the $31^{\text {st }}$ March 2016 (under 18s). This represents an overall stability level of 55\% since 2002.

- Finally, of the $69 \%$ of young people who had been in the same foster care placement between 2002 and 2007, 63\% remained there, without disruption, until their $18^{\text {th }}$ birthday or the $31^{\text {st }}$ March 2016 (under 18s). This represents an overall stability level of $43 \%$ since 2002.

Table 2 shows very high levels of stability stretching back to 2002 for those young people who were adopted, were made subject to Residence Order, and who returned to birth parents, with stability levels being higher if only extending the period back to 2007 (9 years). For the adopted and Residence Order group, the level of placement stability since 2002 was twice as high as that for the foster care group. Although at lower levels than the other placements, around $50 \%$ of the young people in the foster and kinship foster care had remaining in stable placements for the last 14 years through to 18 years old or the $31^{\text {st }}$ March $2016(<18 \mathrm{~s})$, with this rising to 63 and $71 \%$ respectively if only tracking back over the last nine years.

\section{Relational Permanence}

In term of the interviews that have been conducted to date with young people and their parents/carers, all bar two of the young people were either living with or in regular contact with their parents or carers. All of the parents and carers interviewed considered or had considered the young people as their children or grandchildren (depending on their age and relationship with the child, and in some cases, despite the emotional anguish it was creating), and that was reciprocated by the majority of the young people. All the non-birth parents and carers had explained how they had treated and raised the young people the same way as they did with their own children. Young people invariably expressed their gratitude to their parents or carers. Most called them 'mum and dad', others 'granny/granddad/aunt/uncle', and two siblings called their foster carers by name, but when they were talking to other people referred to them as their parents. 
Six of the 30 young people had suffered a placement breakdown or disruption from the parents/carers that we interviewed. However, in all but one case, their relationship had continued despite the young person no longer being in placement, and the young people's feelings of belonging to that family and identifying it as their home (or one of their homes) remained through the years. In the following subsections, we explore these issues in more detail.

\section{Sense of belonging}

The parents and carers interviewed talked about their parental and loving feelings for the young people they cared for. These were stated very explicitly by the adoptive parents, who felt very attached to the young people:

"I feel very close to him, I think I would feel the same as if he had been born by [adoptive mum's name]. I don't feel there is any difference. Well, I'll tell you what. I feel I love him more. And I say to Dave 'Look, you needed us and we needed you, and that's why we are extra especial'. So, I think he understands that." (Dave's adoptive father)

Similarly, the majority of Residence Order, foster and kinship foster carers felt a strong parental bond for the young people, and some acknowledged the struggle that the young people may be having, or have had, about who to call "mum and dad". For instance, Jim (aged 20) was looked after by his grandfather and step-grandmother under a Residence Order, and she said this about him:

"One day at school he came home in tears and I said 'what's wrong son?' and he said [other boy's name] said you aren't my mum and dad'. I said 'Jim, come here, sit down a wee minute darling. You know we aren't your mum and dad, you know your dad is your granda, you know I am only [my name], it is up to you ... call me mum if you want and call him dad if you want, and never listen to other kids, son ... to be quite honest, I would die for him. He is my son, that's the way I look at it." The young people reciprocated the comments given by the parents/carers. For instance, Jim explained he called his carers mum and dad, and added: 
"... and as far as I'm concerned, they will always be."

Belinda (aged 20) was also raised by her grandparents (in kinship foster care), and also considered them as parental figures:

"... they basically are like my parents ... I am very close to my grandparents, so I am. I am here every day torturing them ... if I didn't have my granny and granddad, I don't know what I would do." Some young people displayed attachments not just to the parents/carers we interviewed. For instance, Linda (aged 21) was looked after by her aunt and uncle under a Residence Order, but used to go to her birth parents at the weekend as she was growing up. She called home more than one place, including her aunt and uncle's, but also her mum's house, and her own house now with her boyfriend:

"I go more to them (aunt and uncle) for advice than my mum, because my mum is very quietnatured. Yeah ... just really another set of parents to go to."

There were some other young people who also felt home was different places. These were less likely to be young people who had been adopted. Anna (aged 19) was raised in foster care, and now lived in supported accommodation and had a toddler. She called 'home' both her foster parents' home and her boyfriend's parents' home. She felt her foster parents were always there for her, and that she could call in anytime. Maeve (aged 19), who had lived with her grandmother, with some friends, and finally with her aunt, also had all these different places to call 'home'. This fact did not constitute a conflict of loyalties for most of these young people. In addition, some (like Anna) had partners and children of their own, thus they were forming another home for themselves, which did not replace the home they had lived in, but added to it.

\section{Placement breakdowns/disruptions that did not result in ending of relationships}

From the group of young people who have been interviewed to date for wave four of the study, there have been six breakdowns/disruptions. These occurred in different placements and within 
different contexts: one was an adoptive placement; two were kinship foster care; and three were foster care placements. In all instances, this caused a great deal of anguish and grief for both the young people and their parents/carers. In this section, each of these cases is explored in some detail.

Edgar (aged 20) had a range of complex physical, emotional and behavioural issues when he came into the care of his last foster carers at three years old. He had already been in many different placements, toing and froing from the birth parents to temporary foster placements since he was one year old. He was later diagnosed with ADHD and Asperger's. The foster family and Edgar developed a strong bond. He was seen as part of the family by the wider foster family (sisters, i.e. foster parents' birth daughters; grandparents; etc.). In the teenage years, his emotional and behavioural difficulties were more challenging to manage for the family, as he became more aggressive and "levitated" to the company of risk-taking older boys, whilst also starting to self-harm.

The foster parents asked for extra support, but appropriate care and treatment for his mental health and behavioural problems was not provided when it was needed, and Edgar was eventually removed from the family by the police when he was 13 . The police had been in the house two nights in a row because of his anger and extremely violent behaviour, which became a risk for the family. The family thought that the removal would be only temporary and things would settle. They did want him back, and fought to get him back, as they were "devastated". They thought that "a couple of nights in a police cell would have cured him". However, the decision was taken out of their hands and he was placed in a residential care unit, followed by a number of moves to different units in the following years.

He was drawn to the older boys in the units, and immediately began to use drugs. Since then, he has been on life support on four occasions resulting from drug overdose, and he has also been severely beaten by drug dealers (due to him owning them money). As a result of these incidents, he is now physically disabled, but living independently in privately rented accommodation. 
Despite his difficulties, Edgar maintained contact with his foster family, and never lost contact with them. For many years, he would have visited and even stayed in their house, and the foster parents visited him too. He still considers them to be his parents, and they are key people in his life. Edgar's foster dad remains very emotionally attached to him and finds it difficult to cope with this relationship because of the Edgar's risk-taking behaviours and mental health difficulties. A few months previous to the interview, Edgar seemed to be turning his life around, but after he found one of his friends dead (after committing suicide), and had a health scare, things started to go downhill again, with him continuing to use drugs, and attempting suicide himself (as he was in debt to the drug dealers), finally ending up in intensive care:

"He's still my son. He's breaking my heart at the minute ... Family here made me take a step back. ... I haven't spoken with him all week until today ... But today he rang me for advice because he did not know what he was going to do because... He is waiting on the paramilitaries that run that estate because it's a tight estate ... apparently they are looking for him now to give him a beating because they think he's dealing. He might be, I don't know ... I love Edgar, and I am the closest thing on this Earth that he has, and [my wife] is in there, very close second, only she's more of a realist than I am, you know, I still see fluffy clouds ... But it is very tough, very tough ... You get so angry with him at the same time ... he always takes the wrong advice ... I don't think he has a future. He has admitted to me that he is not going to be long in this life." (Edgar's foster father)

Sophie (aged 22) had had a range of placements with a number of her aunts, until eventually she went to live with her great aunt when she was seven years old. Although she had behavioural problems, she had a very good relationship with the great aunt and uncle, where she was treated the same as their own children and grandchildren. She also did very well in school. However, when she went into secondary school and in her teenage years, she began to clash with them and their relationship deteriorated. According to her kinship foster parents, she lied to them on several occasions and broke their trust regarding her relationship with her older boyfriend, and her 
relationship with her birth father. According to Sophie, she clashed with her great aunt and during her teenage years began to feel uncomfortable living in the placement. She also resumed contact with her birth father, because he meant so much to her, but her foster parents did not approve. They saw him as a danger to her, due to him having been abusive to her mother, and his anti-social, risk-taking and aggressive behaviours.

Sophie eventually moved into her own apartment, with Social Services support, when she was 17 years old. Although she lives very close to her kinship foster carer's home, they have not been in touch since then, i.e. for five years. This is the only case where we have witnessed a complete breakdown of the relationship after the young person moved out. Both Sophie and her great aunt and uncle are suffering emotionally from this breakdown, and would like their relationship to be restored, especially now (at the time we interviewed them) with Sophie being pregnant with her first child. Sophie expressed her gratitude at having been raised by her kinship foster parents, and they expressed the love they still feel for her:

"When you rear a wee girl, as the months and years go on, you begin to love them as your own child. And we love Sophie, we still do ... I hope she's alright ... I don't forget about her. I never will." (Sophie's great aunt and former kinship foster carer)

"I know that I wouldn't be the way I am, sitting here today, and I wouldn't have a job because I wouldn't have had the work ethic either ... I wouldn't have been the way I was at school if it wasn't for them ... They [my aunt and uncle] just wanted me to do well, and they would have done anything. ... They were very good at getting me everything ... they were absolutely brilliant ... Especially my uncle, it was like it was my daddy ... I would love to have a relationship with them, you know, but my aunt is a very funny-nature person and she sticks by her guns, you know, and she maybe thinks I let her down a wee bit whenever I moved out ... [Crying] I love them, I absolutely love them." (Sophie) Carl (aged 22) went to live with his foster mother and father, their daughter and his birth brother, when he was 3 years old. He had settled well and there were no problems with his behaviour. His 
foster father died when he was seven years old, and when he was 10, his little brother also died of cancer. He was incredibly close to his brother, and found both deaths very difficult to cope with. The foster mother tried to help him as much as she could, but when "he reached puberty", Carl's behaviour became increasingly aggressive and challenging to manage.

Carl had respite care a few times, but when he was 14 years old, it came to a point where his foster mum felt the need to ask Social Services for Carl and herself to have a few weeks' break from each other to help their relationship. However, a new social worker became involved with the family and decided that Carl should move out permanently. The decision was taken out of the foster mother's hands, who did not agree with it and did not feel consulted about it. Both Carl and the foster mother found the end of the placement very difficult to cope with, but they remained in contact. He first moved into a residential unit but only stayed there for a few weeks/months, then went to live with his aunt for 18 months, and then moved in with his birth mum (aged 16). He said he wanted to look after his birth mum, who was a vulnerable woman. Carl would ring the foster mother "on days that she (birth mum) was out of her head" or when he was in trouble. The birth mother used to abuse drugs and throw him out of the house. He got a job as a waiter, and would give his birth mum his wages, "feeding her habit really". Sometimes, he would be starving and would call his foster mum. She would meet him and buy him something to eat. He finally went to live on his own.

Carl has two children from two different mothers. He is currently living with his girlfriend and their child. He has continued to be in touch with his birth mother and all his birth siblings. Recently, he was on life support due to a drugs overdose, which happened when he went to visit his birth mum, and was offered drugs. After this incident, he felt he had to distance himself from his birth mum to stay clear of drugs. The relationship between the foster mother and Carl has persisted since he left the placement. They kept in touch over the years through phone calls and texts. The foster mum remarried, and Carl was at her wedding. According to the foster mother, he is part of the family. He 
visits her regularly with his girlfriend and child, and texts her often. The foster mother considers him her son, and Carl still sees her as his mother:

"We have a love for each other and when he comes in, I mean, he throws his arms around me. You know, such a sincere hug. And I remember him, he would have always said 'You're my mum. [Birth mum] can't be my mum, because she doesn't know how.'"'

Ruairí (aged 22) lived with his foster family from a very young age, but when he turned 13, he started displaying risk-taking and challenging behaviours and "getting in with the wrong crowds". He had been diagnosed with Attention Deficit and Hyperactivity Disorder (ADHD), and also had emotional problems and anger issues. He was angry with his birth mum (with whom he had continuous contact through the years) because he was the only one of his siblings who was placed in care. The foster placement broke down when he was 17 years old, due to threats from neighbours. The fostering agency refused to continue to support the placement in these circumstances. He moved into a residential care unit.

Despite the placement breaking down, the relationship between Ruairi and his foster mother continued and they remained in regular contact. She explained how she still feels like his mother, and that he is part of the family. However, because of his past behaviour and some incidents of violence, other people in the family (i.e. her birth daughter) were estranged from him. According to the foster mother, Ruairí still considers her his mother:

"He would turn around and say 'You're my ma', he says, 'she's (birth mum) not'".

Sarah (aged 18) was adopted when she was a baby with her older birth sister. They both settled in well with their adoptive family. She was an extremely intelligent girl, but during her last two years in primary school her behaviour changed dramatically and became extremely problematic and risky. Her teachers also noticed a change in her attitude. She began skipping school at 12 years of age, and only remained in secondary school for one and a half years. On her first year in secondary school, 
the adoptive parents became aware that Sarah and other girls had been abusing aerosols, and they rang the school, but according to the adoptive mother, the school did not deal with it effectively. The adoptive mother asked for help from Social Services, but this never materialised until the events had escalated.

Before the adoption disruption, Sarah was reported missing to the police on various occasions when she was 13 years old, while her risk-taking, anti-social and violent behaviours increased. The adoptive parents found it increasingly hard to cope. Social Services and other agencies eventually became involved. According to the adoptive mother, Social Services blamed herself and her husband (as Sarah made unfounded allegations against them). A particular social worker caused a lot of upset to the adoptive parents, and they ended up putting in a complaint.

Eventually, Sarah moved out of the family home at 13 years of age and went into a residential care unit. Her aggressive behaviour became so challenging that even the staff in the residential home found it hard to control her. Sarah became pregnant at 14 years old. She returned to the adoptive family home when she was heavily pregnant. However, a few weeks after the baby was born, when she was 15 , her risk-taking behaviours re-appeared, and she abandoned her baby. A judge deemed Sarah a risk for the baby, and according to the adoptive parents she was given the choice as to whether she lived with the adoptive parents or her baby did (both could not live together). They indicated that she chose for the baby to live with them, and her two-year old lives now with the adoptive parents.

Sarah keeps in touch and visits her adoptive parents, but her contact is sporadic, and they often don't hear from her for days and weeks at a time. Sarah suffers from palpitations, behavioural problems, including hyperactivity, and emotional problems (depression, talks about killing herself, suspected personality disorder). She also displays risk-taking behaviours, including alcohol and drug abuse. Sarah's adoptive mother still considers Sarah her daughter, but she is not positive about her future. She also feels very protective of her grandchild: 
"I still hope against hope that things are going to change but ... [My husband] and I are of the firm opinion now that she is who she is. She's not going to change, even with maturity. I'm not that optimistic ... She's our daughter, she's our eldest daughter and we still love her very much, but everything now is about [Sarah's child]. The child is the youngest member of our family ... We have to move forward."

Maeve (aged 19) lived with her paternal grandparents and their son and extended family in a kinship placement since she was a baby. She was very settled in the placement. Both her birth parents had significant mental health problems, and had met in a residential mental health unit. She regularly visited her birth father, but the contact with her birth mother had stopped when she was around three years old. When she was 11 or 12 years old, her grandfather died. Her grandmother found it difficult to cope and started abusing alcohol. Maeve also found it hard (coupled with bullying at school), and her mental health deteriorated. She had been self-harming since she was about 10. This was not noticed by Social Services until she attempted suicide when she was 15 years old. At that point, she was removed from her grandmother, and had three temporary placements (with an aunt first, and then two friends) before moving permanently to live with her paternal uncle.

During these years, she continued visiting, and stayed in touch regularly with her grandmother, who stopped abusing alcohol. Their bond has remained strong over the years, and she still has a room in her grandmother's home. She considers her granny, her uncle, her friends and her counsellor the most important people in her life. At the time of the interview, she was moving to a city in England to start a university course.

"I mean I would talk to my nannie about most things, like even it was, not that I'd do drugs, but even about drugs I would be able to tell her, and boys. Whereas my uncle, I wouldn't really tell him as much not that he would crack up or anything, but if I needed to tell him then I would. But if I don't feel it is necessary to tell him, I would just tell my counsellor." 
As revealed by these specific cases of breakdown/disruption, placements can terminate for multiple reasons and as a result of very complex situations. A common factor appeared to be a lack of support from mental health services at the appropriate time. Other factors include the young people's extreme emotional and behavioural problems, their feelings of anger and abandonment, or their distressing experiences of bereavement, bullying or alcohol/substance abuse. However, what all these cases reflect is the strength of the bond that young people and their long-term carers and parents build over the years, to such an extent that even when placements become difficult and end, these relationships and feelings of belonging very often persist.

\section{Discussion}

One of the criticisms that care systems face across the world is the instability of the care experience, with Ainsworth and Hansen (2014) stating that "for far too many children and youth, foster care does not provide permanence, in fact it only offers 'impermanence', through placement instability" (p.89). The findings of the current study would suggest that, as far as the system that operates in Northern Ireland is concerned, which is very similar to that in Great Britain (England, Wales and Scotland), this criticism does not fully apply, for a number of reasons.

First, as shown in the figures presented in Tables 1 and 2, we found very high levels of placements stability, across a 14 year period, for children who were adopted, were placed on Residence Order, and who were rehabilitated to their birth parents. It is important to bear in mind that these are placements that were provided for these children whilst they were within the care system. The care system acted as a gateway to these high levels of stability. Entry to care was an essential first step to being provided with highly stable placements outside of the care system. This could not have been achieved without initial entry to the care system, and as such, the care system can be credited to a large extent for enabling these children to have stability throughout childhood.

Second, the findings confirm what has already been demonstrated by numerous other studies (Biehal et al., 2010; Sellick et al., 2004; Selwyn \& Quinton, 2004; Sinclair, 2005; Ward et al., 2003; 
Wilson et al., 2004), which is that level of placement stability is higher in adoption (and on Residence Order) than in long-term foster and kinship foster care. In fact, the level of stability over a 14 year period up to 18 years old was twice as high in adoption than in foster care.

Does this mean that the criticism highlighted by Ainsworth and Hansen is justified? We would argue not. The current findings do show a marked difference between adoption and foster care, but the level of stability over a 14 year period for foster care is still close to $50 \%$, so long-term foster care is not 'only offering' instability, but stability through to 18 for one in every two children who entered care under the age of five and progressed into long-term foster placement. If the nine year period prior to turning 18 years old is considered, this level rises to around $70 \%$. We would argue that this is a significant achievement, particularly when one considers the statutory obligations upon Social Services to begin to plan for independence with these young people from the mid-teens, and how these systemic processes can sometimes create the conditions for early exit.

Thirdly, when we spoke to the young people themselves, we found that all bar one, irrespective of placement type, had developed a sense of belonging and connection to the family, which continued until early adulthood. This was as strong for those in foster and kinship foster care, as it was in adoption, on Residence Order and rehabilitated to birth parents. It could not be argued that the care system has not provided these children with, or enabled them to achieve, permanence in their lives.

The findings of the study also allow us to better understand the relationship between placement stability and relational permanence. It would appear from the initial group we have interviewed to date in the fourth wave of the study, that placement stability may be directly related to relational permanence. In other words, all those children who were provided with placement stability through to 18 years (or the $31^{\text {st }}$ March 2016 for $<18$ s) also had relational permanence. Irrespective of placemen type. They were all highly attached and committed to their parents/carers and families and were keen that these relationships should persist throughout their lifetimes. This was not 
unexpected. What was unexpected was the extent to which this continued to persist even where the placement had broken down/disrupted, particularly in foster and kinship foster care, even if this had been highly upsetting and emotionally traumatic for all involved.

This suggests that once the stability of a placement enables the formation of strong relationships, those relationships are likely to sustain even in the absence of the placement itself. This was clearly evident in the case of Edgar, where the placement had broken down when he was 12 years old, but was still part of the foster family 10 years later, when we visited himself and his foster family for the current wave of the study.

It would appear that although foster and kinship foster care placements may not persist as long as adoptive, Residence Order and birth parents placements, they have the same capacity to provide relational permanence through to early adulthood (so long as the children can enter them at a young age, and they can persist for long enough for strong parental and wider family relationships to be established). The findings presented in Table 2 indicate that as many as $78 \%$ of children in kinship foster care and $69 \%$ in foster care were in the same placement over a five year period between 2002 and 2007, when they were aged between two and seven years old, a critical period for the formation of parental attachments. Our initial findings would suggest that even if these placements were to break down at some point before the age of 18 , it would be likely that the relationships would persist, suggesting potentially very high levels of relational permanence being provided for these foster children.

\section{Limitations of the study and future steps}

Fieldwork interviews for this wave of the study has only recently begun, and as such, it needs to be recognised that the qualitative findings presented in this paper only capture part of the story of the lives of this population of young people and their relationships with their parents and carers. However, as we continue to interview more families, the extent to which relational permanence is maintained within all the different types of placement will become more evident. We should also be 
able to gather more evidence of the specific circumstances of placements breakdown/disruption or/and when relationships deteriorate; and what might be done to avoid this occurring.

There are a number of other potential limitations to the study. First, not all the key people involved in the young people's lives are interviewed, including social workers or previous carers, so we are only able to develop a partial picture of their lives. Second, we are aiming to recruit $50 \%$ of the study population, which means that we will not know the experience of half the population, but the hope is that the group interviewed will be sufficiently representative of the study population.

Furthermore, even this $50 \%$ recruitment level will be challenging to achieve due to difficulties in locating the young people and families, as some of them might not have had any contact with Social Services for many years, especially if they were returned to their birth parents shortly after the study started and their care order was removed, or if they were adopted and had had no contact with Adoption UK or any other agency. In addition, some young people may have emigrated to other countries, and some might be in prison or mental health institutions, or homeless, which makes their participation unlikely. Despite these challenges, we remain confident of reaching a $50 \%$ recruitment level based on our success levels in other similar studies.

\section{Conclusions and implications for policy and practice}

Our findings have clear implications in terms of policy and practice. Placement breakdown or disruption occurs more often within foster and kinship foster care placements, than in adoption, Residence Order, or when rehabilitated to birth parents. This is commonly interpreted as the end of the relationship between the young people and their foster carers, and as failure of the placement. Although only in the initial stages of interviews, we have found that in most cases, the relationships that are established in these long-term placements do not disappear when the placement ends. This appears to be because the children have entered these placements at a young age, and they have persisted long enough for strong reciprocal attachment relationships to have formed. 
Consequently, if these placements do breakdown at some point before the age of 18 , this should not be deemed the end of these relationships and as a failure by Social Services, but more of a physical transition, with emotional relationships remaining intact. As such, greater effort should be made by Social Services to maintain contact between young people and foster parents/carers following breakdown/disruption (if both parties so wish), so as to ensure that they can continue to benefit from the supportive and emotional aspects of those relationships.

The evidence suggests that relationships with parents or parental figures are key for young adults' wellbeing (Cushing, Samuels, \& Kerman, 2014). However, practitioners tend to overlook the importance of these relationships once the placement ends, and Social Services need to recognise these relationships and even support them to continue and thrive. This is particularly the case considering the importance of such bonds for the young people's wellbeing, and the grief these families have endured in the aftermath of a placement disruption. Foster and kinship foster parents/carers should be seen as a source of vital social and emotional support for young people, not only as they leave the care system, but also when disruption occurs, and this should be properly recognised.

The findings would also suggest that young children should be placed with long-term foster and kinship foster carers at the earliest possible point, to help build the foundations for future supportive relationships. This study also challenges the notion that only adoption can create a stable and enduring bond between the parent/carer and the young person, and a sense of family belonging, which survives into adulthood. Consequently, long-term foster care and long-term kinship foster care, alongside the use of Residence Order, return to birth parents, should also be seen as placements that are capable of persisting through to 18 years old, and providing relational permanence for the children, and families for life. 


\section{Acknowledgements}

We would like to thank all the young people, parents and carers who have taken the time to participate in this wave of the study to date, in addition to the professionals who helped support the development of the materials and recruitment process, specifically across the five Health and Social Care Trusts in Northern Ireland, and within Adoption UK, the Fostering Network, and VOYPIC. We would also like to acknowledge the contribution of Teresa Rushe who assisted with the funding application to the Economic and Social Research Council (ESRC), and finally to thank the ESRC for seeing the value of longitudinal research in this important area of work. 


\section{References}

Ainsworth, F. \& Hansen, P. (2014). Family foster care: Can it survive the evidence? Children Australia, 39 (2), 87-92.

Aldgate, J., \& Jones, D. (2005). The place of attachment in children's development. In J. Aldgate, D. Jones, W. Rose and C. Jeffrey (Eds.), The developing world of the child. London: Jessica Kingsley Publishers.

Andersen, S.H. \& Fallesen, P. (2015). Family matters? The effect of kinship care on foster care disruption rates. Child abuse \& neglect, 48, 68-79.

Beek, M.J. (2014). Security and permanence in long-term foster care: Family relationships and professional systems. PhD Thesis (April 2014). Norwich: University of East Anglia.

Biehal, N., Ellison, S., Baker, C. \& Sinclair, I. (2010). Belonging and Permanence: Outcomes in longterm foster care and adoption. London: BAAF.

Braun, V. \& Clarke, V. (2006). Using thematic analysis in psychology. Qual. Res. Psych., 3, 77-101.

Cashmore, J. \& Paxman, M. (2006). Predicting after-care outcomes: The importance of 'felt' security. Child \& Family Social Work, 11(3), 232-241.

Cushing, G., Samuels, G.M. \& Kerman, B. (2014). Profiles of relational permanence at 22: Variability in parental supports and outcomes among young adults with foster care histories. Children and Youth Services Review, 39, 73-83.

Hedin, L. (2017). Support and challenges in the process of leaving care: A Swedish qualitative followup study of foster youth's lived experiences. Qualitative Social Work, 16(4), 500-514.

Lowe, N. \& Murch, M., with Bader, K., Borkowski, M., Copner, R., Lisles, C. \& Shearman, J. (2002). The Plan for the Child: Adoption or Long-term Fostering. London: BAAF. 
McSherry, D., Fargas Malet, M. \& Weatherall, K. (2013). Comparing long-term placements for young children in care: The care pathways and outcomes study - Northern Ireland. London: British Association for Adoption and Fostering (BAAF).

McSherry, D., Fargas Malet, M. \& Weatherall, K. (2016). Comparing long-term placements for young children in care: Does placement type matter? Children \& Youth Services Review, 69, 56-66.

Oosterman, M., Schuengel, C., Slot, N.W., Bullens, R.A. \& Doreleijers, T.A. (2007). Disruptions in foster care: A review and meta-analysis. Children and Youth Services Review, 29(1), 53-76.

Rock, S., Michelson, D., Thomson, S. \& Day, C. (2013). Understanding foster placement instability for looked after children: A systematic review and narrative synthesis of quantitative and qualitative evidence. British Journal of Social Work, 45(1), 177-203.

Rubin, D.M., O'Reilly, A.L.R., Luan, X. \& Localio, A.R. (2007). The impact of placement stability on behavioral well-being for children in foster care. Pediatrics, 119, 336-344.

Rutter, M. (1995). Clinical implications of attachment concepts: Retrospect and prospect. Journal of Child Psychology and Psychiatry, and Applied Disciplines, 36(4), 465-476.

Samuels, G.M. (2009). Ambiguous loss of home: The experience of familial (im)permanence among young adults with foster care backgrounds. Children and Youth Services Review, 31(12), 1229-1239. Sanchez, R.M. (2004). Youth perspectives on permanency. San Francisco, CA: California Permanency for Youth Project.

Schofield, G. (2003). Part of the Family. London: BAAF.

Schofield, G. \& Beek, M. (2009). Growing up in foster care: Providing a secure base through adolescence. Child and Family Social Work, 7(1), 3-26.

Sellick, C., Thoburn, J. \& Philpot, T. (2004). What works in adoption and foster care? London: Barnado's/BAAF. 
Selwyn, J. \& Quinton, D. (2004). Stability, permanence, outcomes and support: Foster care and adoption compared. Adoption \& Fostering, 28(4), 6-15.

Selwyn, J., Sturgess, W., Quinton, D. \& Baxter, C. (2006). Cost and Outcomes of non-infant Adoptions. London: BAAF.

Selwyn, J., Wijedasa, D. \& Meakings, S. (2014). Beyond the Adoption Order: Challenges, Interventions and Adoption Disruption. Research Report. London: Department for Education.

Semanchin Jones, A. \& LaLiberte, T. (2013). Measuring youth connections: A component of relational permanence for foster youth. Children and Youth Services Review, 35(3), 509-517.

Sinclair, I. (2005). Fostering now: Messages from Research. London: Jessica Kingsley Publishers.

Sinclair, I., Baker, C., Wilson, K. \& Gibbs, I. (2003). What Happens to Foster Children? Report 3 of the Supporting Fostering Project. York: Social Work Research and Development Unit, University of York.

Sinclair, I., Baker, C., Wilson, K. \& Gibbs, I. (2005). Foster children: Where they go and how they get on. London: Jessica Kingsley.

Sinclair, I., Wilson, K. \& Gibbs, I. (2000). Supporting Foster Placements: Report 2 of the Supporting Fostering Project. York: Social Work Research and Development Unit, University of York.

Thoburn, J. (1991). Evaluating placement: An overview of 1,165 placements and some methodological issues. In J. Fratter, J. Rowe, D. Sapsford, \& J. Thoburn (Eds.), Permanent Family Placement. London: BAAF.

Thoburn, J., Norford, L. \& Parvez Rashid, S. (2000). Permanent Family Placement for Children of Minority Ethnic Origin. London: Jessica Kingsley.

Thompson, A.E. \& Greeson, J.K.P. (2015). Legal and relational permanence in older foster care youths. Social Work Today, 15(4), 24. 
Triseliotis, J. (2002). Long-term foster care or adoption? The evidence examined. Child and Family Social Work, 7(1), $23-33$.

Vinnerljung, B., Sallnäs, M. \& Berlin, M. (2017). Placement breakdowns in long-term foster care - A regional Swedish study. Child and Family Social Work, 22, 15-25.

Ward, H., Munro, E.R., Dearden, C. \& Nicholson, D. (2003). Outcomes for looked after children: Life pathways and decision-making for very young children in care or accommodation. Loughborough: Centre for Child and Family Research.

Ward, H., Munro, E.R. \& Dearden, C. (2006). Babies and young children in care: Life pathways, decision-making and practice. London: Jessica Kingsley Publishers.

Wilson, K., Sinclair, I., Taylor, C., Pithouse, A. \& Sellick, A. (2004). Fostering success: An exploration of the research literature in foster care. London: SCIE. 